\title{
Grammatical Issues in Saudi EFL Writings: A Minimalist Approach
}

\author{
Mohammad Alkhatib \\ Prince Mugren University, Saudi Arabia
}

\begin{abstract}
This empirical study is an analysis of EFL writing by third year university students. There are three aims of the current work; (1) to find out the kinds of grammatical errors Saudi students make in their writings; (2) to explicate ungrammaticality of the students' errors employing the Minimalist Program; (3) to evaluate the contributing factors that cause grammatical errors. Data was derived from compositions written by a stratified random sample of twenty junior students majoring in English department at Faculty of Arts and Humanities in King Abdul Aziz University, Jeddah, Saudi Arabia. In view of this, these compositions are an assignment given by their lecturer as a kind of critical writing about the play Trifles by Glaspell. The study is qualitative in nature as it primarily focuses on analyzing the types of grammatical errors no matter how frequent they occur. Findings revealed that most of the grammatical errors are in sentence structure, prepositions, subject-verb agreement and wrong use of words. The results demonstrated that Saudi juniors do not completely fulfill the requirement for lexical information of an English sentence in the sense they still do not fully understand how many arguments a verb must have, what features a verb may have in terms of transitivity, intransitivity or even what kind of phrase that a verb subcategorizes for. With regard to factors causing ungrammaticality, intra-language errors were the majority of the grammatical errors in the writings whereas mother-tongue interference has no great influence on the students' writing. Saudi EFL students seem to over-generalize English rules to other positions in sentence structure. Also, they are not aware, sometimes, of the exceptions or restrictions of a rule which results in ill-formed structure.
\end{abstract}

Key words: Minimalist Program, X-bar theory, inta-lingual issues, inter-language issues 